\title{
Advancing diagnostic hematopathology: pigeons or pixels?
}

\section{William R. Macon ${ }^{1}$}

Published online: 18 May 2019

(C) Springer-Verlag GmbH Germany, part of Springer Nature 2019

Levenson and colleagues recently demonstrated that pigeons (Columba livia) could distinguish between relatively straightforward benign and malignant breast tissue on digitally scanned hematoxylin and eosin-stained 5- $\mu \mathrm{m}$ sections of formalin fixed, paraffin-embedded breast (at a maximum resolution of $20 \times$ ) at different levels of magnification after training with food reinforcement [1]. Single pigeons made $85 \%$ correct choices following 15 days of training; however, a cohort of four birds achieved a group accuracy level of $99 \%$. Of course, these results do not suggest that diagnostic pathologists can be replaced by a flock of pigeons.

On the other hand, an emerging disruptive technology that pathologists need to embrace for augmenting work-flow standardization and efficiency, diagnostic accuracy and reproducibility, and practice quality and patient safety is digital pathology using whole slide imaging (WSI) systems. There is a body of literature that already shows that digital pathology is equivalent to standard light microscopy for diagnostic accuracy in surgical pathology, and that, with appropriate training and experience among the study pathologists, it can be accomplished without a significant lengthening of case turn-around-time [2, 3]. Digital pathology by WSI is now being used for primary surgical pathology diagnostics in several European countries, Singapore, Canada, and Japan [2]. Opportunities for using this technology now exist in the USA since the recent approval of the Phillips IntelliSite Pathology Solution by the US Food and Drug Administration for primary surgical pathology diagnosis [4]. Individual institutions must decide if implementing this technology is to their benefit $[3,5]$.

But what about hematopathology? Our field is one of the areas regarded as having limited studies on the use of digital pathology on WSI [6]. Some of these published studies include quantification of fibrosis and osteosclerosis in myeloproliferative neoplasms [7], estimates of adult bone marrow

William R. Macon

Macon.William@mayo.edu

1 Mayo Clinic, Rochester, MN, USA biopsy cellularity [8], and evaluation of MYC protein expression by immunohistochemistry [9]. By applying deep machine learning with a convolutional neural network algorithm, a recent study provided a proof-of-concept for a lymphoma diagnostic model [10]. Deep learning to develop diagnostic algorithms for digital hematopathology will be a significant future endeavor.

Like cytopathology, additional technical challenges are encountered in some aspects of digital hematopathology not faced in surgical pathology. High magnification, such as with oil immersion objectives, requires multi-planar scanning and z-stacking of images [5]. When this has been applied to hematopathology tumor boards, there appears to be considerable satisfaction [11].

Now, back to breast pathology, a recent study using digital pathology for the primary diagnosis of breast pathology specimens by three specialty breast pathologists showed complete clinical concordance between glass slide and digital impressions in $98.8 \%$ of cases [12]. While a reassuring result when compared to the pigeons, the study did not state whether or not the participants received food reinforcement.

\section{References}

1. Levenson RM, Krupinski EA, Navarro VM, Wasserman EA (2015) Pigeons (Columba livia) as trainable observers of pathology and radiology breast cancer images. PLoS One 10(11):e0141357

2. Van Es SL (2019) Digital pathology: semper ad meliora. Pathology $51: 1-10$

3. Baidoshvili A, Bucur A, van Leeuwen J, Kluin P, van Diest PJ (2018) Evaluating the benefits of digital pathology implementation: time savings in laboratory logistics. Histopathology 73:784-794

4. Evans AJ, Bauer TW, Bui MM, Cornish TC, Duncan H, Glassy EF, Hipp J, McGee RS, Murphy D, Myers C, O'Neill DG, Parwani AV, Rampy A, Salama ME, Pantanowitz L (2018) US Food and Drug Administration approval of whole slide imaging for primary diagnosis. A key milestone is reached and new questions are raised. Arch Pathol Lab Med 142:1383-1387

5. Evans AJ, Salama ME, Henricks WH, Pantanowitz L (2017) Implementation of whole slide imaging for clinical purposes. Issues to consider from the perspective of early adopters. Arch Pathol Lab Med 141:944-959 
6. Saco A, Ramirez J, Rakislova N, Mira A, Ordi J (2016) Validation of whole-slide imaging for histopathological diagnosis: current state. Pathobiology 83:89-98

7. Teman CJ, Wilson AR, Perkins SL, Hickman K, Prchal JT, Salama ME (2010) Quantification of fibrosis and osteosclerosis in myeloproliferative neoplasms: a computer-assisted study. Leuk Res 34: 871-876

8. Hagiya AS, Etman A, Siddiqi IN, Cen S, Matcuk GR, Brynes RK, Salama ME (2018) Digital image analysis agrees with visual estimates of adult bone marrow trephine biopsy cellularity. Int J Lab Hematol 40:209-214

9. Hupp M, Williams S, Dunnette B, Tessier KM, Courville EL (2019) Comparison of evaluation techniques, including digital analysis, for MYC protein expression by immunohistochemical stain in aggressive B-cell lymphomas. Hum Pathol 83:124-132

10. Achi HV, Belousova T, Chen L, Wahed A, Wang I, Hu Z, Kanaan Z, Rios A, Nguyen AND (2019) Automated diagnosis of lymphoma with digital pathology images using deep learning. Ann Clin Lab Sci 49:153-160

11. Chen ZW, Kohan J, Perkins SL, Hussong JW, Salama ME (2014) Web-based oil immersion whole slide imaging increases efficiency and clinical team satisfaction in hematopathology tumor board. J Pathol Inform 5:41

12. Williams BJ, Hanby A, Millican-Slater R, Nijhawan A, Verghese E, Treanor D (2018) Digital pathology for the primary diagnosis of breast histopathological specimens: an innovative validation and concordance study on digital pathology validation and training. Histopathology 72:662-671

Publisher's note Springer Nature remains neutral with regard to jurisdictional claims in published maps and institutional affiliations. 